\title{
Clinical efficacy of high-flow nasal cannula compared to noninvasive ventilation in patients with post-extubation respiratory failure
}

\author{
Jung-Wan Yoo ${ }^{*}$, , Ara Synn ${ }^{*}$, Jin Won Huh, Sang-Bum Hong, Younsuck Koh, and Chae-Man Lim
}

Department of Pulmonary and Critical Care Medicine, Asan Medical Center, University of Ulsan College of Medicine, Seoul, Korea

Received: September 2, 2014 Revised : October 21, 2014 Accepted: October 21, 2014

\section{Correspondence to}

Chae-Man Lim, M.D.

Department of Pulmonary and Critical Care Medicine, Asan Medical Center, University of Ulsan College of Medicine, 88 Olympic-ro 43-gil, Songpa-gu, Seoul 05505, Korea

Tel: +82-2-3010-3135

Fax: $+82-2-3010-6968$

E-mail: cmlim@amc.seoul.kr

*These authors contributed equally to this work.

${ }^{\dagger}$ Current affiliation: Department of Internal Medicine, Gyeongsang National University Hospital, Jinju, Korea
Background/Aims: Post-extubation respiratory failure (PERF) is associated with poor clinical outcomes. High-flow nasal cannula (HFNC) oxygen therapy has been used in patients with respiratory failure, but the clinical benefit in patients with PERF remains unclear. The aim of this study was to evaluate the clinical efficacy of HFNC compared to noninvasive ventilation (NIV) in patients with PERF. Methods: A historic retrospective cohort analysis was performed in 28 beds in the medical Intensive Care Unit (ICU) at a single medical center in South Korea. In total, 73 patients with PERF were enrolled: 39 patients who underwent NIV from April 2007 to March 2009 and 34 patients who received HFNC from April 2009 to May 2011.

Results: The rate of avoidance of reintubation was not different between the HFNC group (79.4\%) and NIV group $(66.7 \%, p=0.22)$. All patients with HFNC tolerated the device, whereas five of those with NIV did not tolerate treatment $(p$ $=0.057$ ). The mean duration of ICU stay was significantly shorter in the HFNC group than in the NIV group (13.4 days vs. 20.6 days, $p=0.015)$. There was no difference in ICU or in-hospital mortality rate.

Conclusions: HFNC is likely to be as effective as, and better tolerated than, NIV for treatment of PERF.

Keywords: Post-extubation respiratory failure; Noninvasive ventilation; High-flow nasal cannula

\section{INTRODUCTION}

Post-extubation respiratory failure (PERF) occurs in $\sim 10 \%$ to $20 \%$ of patients with planned extubation and results in reintubation [1-3]. Reintubation due to PERF is associated with poor outcomes, including an increased incidence of ventilator-associated pneumonia, increased mortality rates, and longer Intensive Care Unit(ICU) and hospital stays [4-6]. An international consensus conference considered noninvasive ventilation (NIV) to be a promising modality in terms of avoiding reintubation associated with PERF and improving clinical outcomes [7]. However, two randomized clinical trials did not demonstrate a benefit of NIV in terms of avoiding reintubation in patients with PERF [8,9].

A high-flow nasal cannula (HFNC), a relatively new oxygenation device, provides adequate heated humidity in addition to a high flow of oxygen. Due to the high flow rate of gas, HFNC can produce a continuous positive airway pressure effect in the airway, and thus may 
exert a favorable physiologic effect [10]. Due to the combination of these effects, HFNC may serve to improve oxygenation, maintain bronchial hygiene, and alleviate respiratory distress [11]. Several studies have reported the usefulness of HFNC in patients with acute respiratory failure, showing beneficial effects on clinical signs and oxygenation [12-15]. Although one work investigated the clinical outcomes in pediatric, and especially neonatal, populations [16], studies focusing on the clinical outcomes of HFNC—-such as reintubation, mortality, or ICU stay-in adults with PERF. are lacking. The aim of our study was to evaluate the clinical outcomes of HFNC in patients with PERF compared to those of NIV.

\section{METHODS}

\section{Patients}

This historic retrospective study was conducted in a university-affiliated hospital with a 28-bed medical ICU in Seoul, South Korea. Medical record charts were reviewed retrospectively. Two groups were established based on the period of treatment: the first group (NIV group) included patients who received treatment from April 2007 to March 2009, while the second group (HFNC group) included patients who underwent treatment from April 2009 to May 2011. The Institutional Review Board of Asan Medical Center approved this study. The requirement for informed consent was waived due to the retrospective nature of the analysis.

\section{Inclusion and exclusion criteria}

Medical patients $\geq 18$ years old who had been extubated were enrolled. Respiratory failure that developed within 48 hours was regarded as PERF, and NIV or HFNC was performed. Respiratory failure was defined as clinical signs of increased effort on breathing (such as active contraction of the accessory respiratory muscles) that developed within 48 hours of extubation, plus one of the following: (1) respiratory acidosis (defined as an arterial $\mathrm{pH}<7.35$ with a partial pressure of arterial carbon dioxide of $>45 \mathrm{mmHg}$ ); (2) respiratory rate greater than 25 breaths per minute; (3) hypoxemia defined as (partial pressure of oxygen $\left[\mathrm{PaO}_{2}\right] /$ fraction of inspired oxygen $\left[\mathrm{FiO}_{2}\right]<300 \mathrm{mmHg}$ or pulse oxygen saturation $\left[\mathrm{SpO}_{2}\right]$ of $<90 \%$ ). Patients were excluded if they had 'do-not-re- suscitate' status or a previous experience of home bilevel positive airway pressure (BiPAP).

NIV protocol: before undergoing NIV, patients were positioned with their beds at a $45^{\circ}$ angle. The patient put on an orofacial mask to function as an interface. In the pressure support mode with $>4 \mathrm{CmH}_{2} \mathrm{O}$ positive end-expiratory pressure, an initial target estimated tidal volume of $6 \mathrm{~mL}$ per predicted kilogram of body weight and a respiratory rate of less than 24 breaths per minute were set. The $\mathrm{FiO}_{2}$ was titrated to maintain the $\mathrm{SpO}_{2}$ at $>90 \%$.

HFNC (Optiflow; Fisher \& Paykel Healthcare, Auckland, New Zealand) protocol: oxygen was supplied via HFNC, using an initial inspiratory flow rate of $30 \mathrm{~L} / \mathrm{min}$ and was titrated until the respiratory effort of patients was minimized. $\mathrm{FiO}_{2}$ was adjusted to achieve a $\mathrm{SpO}_{2}$ of $>90 \%$.

\section{Data collection}

Avoidance of reintubation, duration of ICU and hospital stay, ICU and hospital mortality rates, and incidence of ICU-acquired pneumonia associated with PERF were evaluated and compared between the two groups. Device intolerance was defined as patients' refusal of continuous use of devices. The avoidance of reintubation was defined as no reintubation due to respiratory failure after applying HFNC or NIV during the ICU stay.

ICU-acquired pneumonia was defined using either clinical criteria (new or progressive radiologic pulmonary infiltrate together with at least two of the following: temperature $>38^{\circ} \mathrm{C}$ or $<36^{\circ} \mathrm{C}$, leukocytosis $>12,000 / \mathrm{mm}^{3}$ or leukopenia $<4,000 / \mathrm{mm}^{3}$, or purulent respiratory secretions) or a simplified Clinical Pulmonary Infectious Score greater than or equal to six points [17].

\section{Statistical analysis}

Categorical and non-categorical variables are expressed as number (percentage) and mean \pm standard deviation, respectively. The Fisher exact or chi-square test was used to compare categorical variables. The Mann-Whitney $U$ test was used for comparisons of non-categorical variables. A value of $p \leq 0.05$ was considered to indicate statistical significance. The SPSS version 18.0 (SPSS Inc., Chicago, IL, USA) was used for data analysis. 


\section{RESULTS}

\section{Baseline characteristics of the enrolled patients}

A total of 73 patients were enrolled in this study: in the first-period group, 39 patients underwent NIV for the treatment of PERF, while in the second-period group, 34 subjects were treated by HFNC. Of all patients, 43 patients $(58.9 \%)$ were males. Their age was $62.6 \pm 16.3$ years. The baseline characteristics of the enrolled patients are shown in Table 1. There was no significant difference in gender, age, or Acute Physiology and Chronic Health Evaluation II or Sequential Organ Failure Assessment score between the two groups. The proportion of neoplasm as an underlying disease was higher in the NIV group than the HFNC group. Acute heart failure was a more common cause of acute respiratory failure in the NIV group than in the HFNC group. Duration of invasive mechanical ventilation until extubation did not differ between the two groups. There was a trend toward shorter duration from extubation to the onset of respiratory failure in the HFNC group.

\section{Physiologic parameters and laboratory data of pa- tients with PERF}

The physiologic parameters and laboratory findings of patients at the onset of PERF are summarized in Table 2. Regarding vital signs, only body temperature differed significantly between the two groups. In the arterial blood gas analysis results, lower $\mathrm{pH}$, higher partial pressure of carbon dioxide, and lower arterial blood saturation were found in the NIV group compared to the HFNC group. There was a trend toward lower levels of sodium and potassium in the HFNC group. Other laboratory data did not differ between the two groups.

\section{Comparison of clinical outcomes between the NIV and HFNC groups}

The clinical outcomes of the NIV and HFNC groups are described in Table 3. Overall, 53 patients (72.6\%) did not

Table 1. Baseline characteristics of the enrolled patients

\begin{tabular}{|c|c|c|c|}
\hline Characteristic & NIV group $(n=39)$ & HFNC group $(\mathrm{n}=34)$ & $p$ value \\
\hline Male sex & $25(64.1)$ & $18(52.9)$ & 0.334 \\
\hline Age, yr & $62.9 \pm 16.1$ & $62.1 \pm 16.8$ & 0.969 \\
\hline Acute Physiology and Chronic Health Evaluation II score & $19.2 \pm 3.9$ & $19.7 \pm 4.1$ & 0.480 \\
\hline Sequential Organ Failure Assessment score & $6.3 \pm 3 \cdot 5$ & $5 \cdot 5 \pm 2.5$ & 0.461 \\
\hline \multicolumn{4}{|l|}{ Underlying disease } \\
\hline Diabetes mellitus & $4(10.3)$ & $5(14 \cdot 7)$ & 0.725 \\
\hline Neoplasm & $11(28.2)$ & $18(52.9)$ & 0.031 \\
\hline Chronic lung disease & $14(35 \cdot 9)$ & $11(32.4)$ & 0.750 \\
\hline Chronic heart disease & $9(23.1)$ & $5(14 \cdot 7)$ & 0.365 \\
\hline Chronic renal disease & $8(20.5)$ & $2(5 \cdot 9)$ & 0.093 \\
\hline Liver cirrhosis & $4(10.3)$ & $3(8.8)$ & 1 \\
\hline \multicolumn{4}{|l|}{ Causes of mechanical ventilation before extubation } \\
\hline Pneumonia & $22(56.4)$ & $18(52.9)$ & 0.766 \\
\hline Sepsis & $8(20.5)$ & $10(29.4)$ & 0.379 \\
\hline AE of chronic obstructive pulmonary disease & $7(17 \cdot 9)$ & $4(11.8)$ & 0.461 \\
\hline AE of idiopathic pulmonary fibrosis & $1(2.6)$ & $4(11.8)$ & 0.177 \\
\hline Acute respiratory distress syndrome & $2(5 \cdot 1)$ & $5(14.7)$ & 0.240 \\
\hline Acute heart failure & $9(23.1)$ & $2(5 \cdot 9)$ & 0.041 \\
\hline Duration of invasive MV before extubation, hr & $182.9 \pm 148.8$ & $132.7 \pm 85.6$ & 0.243 \\
\hline Time elapsed from extubation to respiratory failure, hr & $10.7 \pm 11.6$ & $8.6 \pm 11.8$ & 0.097 \\
\hline
\end{tabular}

Values are presented as number (\%) or mean \pm SD.

NIV, noninvasive ventilation; HFNC, high-flow nasal cannula; AE, acute exacerbation; MV, invasive mechanical ventilation. 
Table 2. Physiologic parameters and laboratory findings of the patients at the onset of post-extubation respiratory failure

\begin{tabular}{|c|c|c|c|}
\hline Variable & NIV group $(n=39)$ & HFNC group $(n=34)$ & $p$ value \\
\hline \multicolumn{4}{|l|}{ Physiologic parameter } \\
\hline Systolic blood pressure, $\mathrm{mmHg}$ & $131.8 \pm 21.2$ & $136.3 \pm 16.9$ & 0.678 \\
\hline Diastolic blood pressure, $\mathrm{mmHg}$ & $64.2 \pm 14.8$ & $71.4 \pm 10.8$ & 0.224 \\
\hline Heart rate, beats/min & $101.9 \pm 21.7$ & $102.6 \pm 18.4$ & 0.799 \\
\hline Respiratory rate, beats/min & $22.8 \pm 5.2$ & $20.9 \pm 6.0$ & 0.115 \\
\hline Body temperature, ${ }^{\circ} \mathrm{C}$ & $36.8 \pm 0.6$ & $36.6 \pm 0.6$ & 0.035 \\
\hline \multicolumn{4}{|l|}{ Arterial blood gas analysis } \\
\hline $\mathrm{pH}$ & $7 \cdot 40 \pm 0.1$ & $7.48 \pm 0.07$ & 0.003 \\
\hline $\mathrm{PaO}_{2}, \mathrm{mmHg}$ & $76.4 \pm 24.2$ & $82.9 \pm 30.3$ & 0.419 \\
\hline $\mathrm{PaCO}_{2}, \mathrm{mmHg}$ & $48.2 \pm 17.8$ & $38.2 \pm 6.6$ & 0.030 \\
\hline $\mathrm{PaO}_{2} / \mathrm{FiO}_{2}$ ratio & $190.6 \pm 82.8$ & $188.9 \pm 73.8$ & 0.757 \\
\hline Pulse oxygen saturation, \% & $93 \cdot 3 \pm 4 \cdot 3$ & $95.2 \pm 3.4$ & 0.032 \\
\hline White cell count, $\times 10^{3}$ cells $/ \mu \mathrm{L}$ & $12 \pm 6.5$ & $13.6 \pm 7.1$ & 0.291 \\
\hline Hemoglobin, g/dL & $9.9 \pm 1.9$ & $10.5 \pm 1.9$ & 0.162 \\
\hline Platelet, $\times 10^{3}$ cells $/ \mu \mathrm{L}$ & $176.3 \pm 133.6$ & $185.8 \pm 110.1$ & 0.425 \\
\hline Albumin, g/dL & $2.5 \pm 0.5$ & $2.6 \pm 0.4$ & 0.456 \\
\hline Sodium, mmol/L & $138.9 \pm 5.5$ & $136.7 \pm 4.2$ & 0.099 \\
\hline Potassium, mmol/L & $3.9 \pm 0.4$ & $3.6 \pm 0.6$ & 0.082 \\
\hline
\end{tabular}

Values are presented as mean $\pm \mathrm{SD}$.

NIV, noninvasive ventilation; HFNC, high-flow nasal cannula; $\mathrm{PaO}_{2}$, partial pressure of oxygen; $\mathrm{PaCO}_{2}$, partial pressure of carbon dioxide; $\mathrm{FiO}_{2}$, inspired fraction of oxygen.

require reintubation during their ICU stay. The rate of avoidance of reintubation was not significantly different between the two groups $(66.7 \%$ for NIV vs. $79.4 \%$ for HFNC, $p=0.223$ ). Device intolerance occurred in five patients (12.8\%) with NIV, whereas there was no device intolerance in patients with HFNC $(p=0.057)$. Four of the five patients that did not tolerate NIV progressed to respiratory failure and were reintubated. In the HFNC group, seven patients progressed to severe respiratory failure, all of whom were reintubated and received invasive mechanical ventilation. A total of 20 patients (27.4\%) were reintubated $33.3 \%$ in the NIV group vs. $20.6 \%$ in the HFNC group, $p=0.531$ ). The rates of reintubation and application of invasive mechanical ventilation were not significantly different between the two groups. The reasons for reintubation were similar in the two groups: refractory hypoxemia was the most common cause (6/39, $46.2 \%$ for NIV vs. $4 / 34,57.1 \%$ for HFNC, $p=0.531$ ). There was no difference in the rate of tracheostomy between the two groups $(6 / 13,46.2 \%$ in the NIV group vs. $4 / 7,57.1 \%$ in the HFNC group, $p=1.0$ ). The duration of ICU stay from extubation was significantly shorter in the HFNC group than in the NIV group (6.8 \pm 9.6 days vs. $10.4 \pm$ 11.1 days, $p=0.013)$, but the duration of ICU stay from the onset of PERF to general ward in ICU survivors did not differ significantly between the groups $(7.8 \pm 9.2$ days in the NIV group vs. $4.6 \pm 5.6$ days in the HFNC group, $p=0.856$ ). The length of hospital stay was similar between the two groups $(52.9 \pm 38.7$ days in the NIV group vs. $48.7 \pm 40.5$ days in the HFNC group, $p=0.367$ ). There was no significant difference in the rate of ICU-acquired pneumonia after extubation (20.5\% in the NIV group vs. $17.6 \%$ in the HFNC group, $p=0.756$ ), ICU (20.5\% in the NIV group vs. $8.8 \%$ in the HFNC group, $p=0.164$ ), or in-hospital mortality (41\% in the NIV group vs. $23.5 \%$ in the HFNC group, $p=0.112$ ) between the two groups.

\section{Subgroup analysis of outcome variables according to the presence of hypercapnia}

Further outcomes analyses according to the presence of hypercapnia were performed since the baseline level of $\mathrm{PaCO}_{2}$ differed significantly between the NIV and 
Table 3. Comparison of clinical outcomes between the NIV and HFNC groups.

\begin{tabular}{|c|c|c|c|}
\hline Variable & $\operatorname{NIV}$ group $(\mathrm{n}=39)$ & HFNC group $(n=34)$ & $p$ value \\
\hline Avoidance of reintubation & $26(66.7)$ & $27(79.4)$ & 0.223 \\
\hline Total reintubation rates & $13(33 \cdot 3)$ & $7(20.6)$ & 0.223 \\
\hline Reasons for reintubation & & & 0.531 \\
\hline Refractory hypoxemia & $6(46.2)$ & $4(57 \cdot 1)$ & \\
\hline Refractory hypercapnia & $3(23.1)$ & o & \\
\hline Excess respiratory secretions & $1(7 \cdot 7)$ & $1(14 \cdot 3)$ & \\
\hline Cardiopulmonary arrest & $2(15 \cdot 4)$ & $1(14 \cdot 3)$ & \\
\hline Changes in mental status & 0 & $1(14 \cdot 3)$ & \\
\hline Lack of improvement in signs of muscle fatigue & $1(7 \cdot 7)$ & o & \\
\hline Tracheostomy & $6 / 13(46.2)$ & $4 / 7(57.1)$ & 1.000 \\
\hline ICU stay, day & $20.6 \pm 14.2$ & $13.4 \pm 10.3$ & 0.015 \\
\hline Post-extubation ICU stay, day & $10.4 \pm 11.1$ & $6.8 \pm 9.6$ & 0.013 \\
\hline ICU stay after PERF in ICU survivors, day & $7.8 \pm 9.2$ & $4.6 \pm 5.6$ & 0.856 \\
\hline Hospital stay, day & $52.9 \pm 38.7$ & $48.7 \pm 40.5$ & 0.367 \\
\hline ICU-acquired pneumonia after extubation & $8(20.5)$ & $6(17.6)$ & 0.756 \\
\hline ICU mortality & $8(20.5)$ & $3(8.8)$ & 0.164 \\
\hline Hospital mortality & $16(41)$ & $8(23.5)$ & 0.112 \\
\hline
\end{tabular}

Values are presented as mean \pm SD or number (\%).

NIV, noninvasive ventilation; HFNC, high-flow nasal cannula; ICU, Intensive Care Unit; PERF, post-extubation respiratory failure.

Table 4. Analysis of outcome variables according to arterial carbon dioxide pressure.

\begin{tabular}{|c|c|c|c|c|c|c|}
\hline \multirow[b]{2}{*}{ Outcome } & \multicolumn{3}{|c|}{$\mathrm{PaCO}_{2}<45 \mathrm{mmHg}$} & \multicolumn{3}{|c|}{$\mathrm{PaCO}_{2} \geq 45 \mathrm{mmHg}$} \\
\hline & $\begin{array}{l}\text { NIV group } \\
\quad(n=22)\end{array}$ & $\begin{array}{l}\text { HFNC group } \\
\quad(\mathrm{n}=28)\end{array}$ & $p$ value & $\begin{array}{l}\text { NIV group } \\
\quad(n=17)\end{array}$ & $\begin{array}{l}\text { HFNC group } \\
(n=6)\end{array}$ & $p$ value \\
\hline Avoidance of reintubation & $14(63.6)$ & $24(85.7)$ & 0.070 & $12(70.6)$ & $3(50)$ & 0.363 \\
\hline ICU mortality & $6(27 \cdot 3)$ & $1(3.6)$ & 0.034 & $2(11.8)$ & $2(33 \cdot 3)$ & 0.270 \\
\hline In-hospital mortality & $9(40.9)$ & $4(14 \cdot 3)$ & 0.033 & $7(41.2)$ & $4(66.7)$ & 0.371 \\
\hline
\end{tabular}

Values are presented as number (\%).

$\mathrm{PaCO}_{2}$, partial pressure of carbon dioxide; NIV, noninvasive ventilation; HFNC, high-flow nasal cannula; ICU, Intensive Care Unit.

HFNC groups (Table 4). In the 50 patients with $\mathrm{PaCO}_{2}$ $<45 \mathrm{mmHg}$, patients with HFNC showed a lower ICU mortality rate (3.6\% vs. $27.3 \%, p=0.034)$ and in-hospital mortality rate ( $14.3 \%$ vs. $40.9 \%, p=0.033)$, as well as a trend toward a lower incidence of reintubation than those with NIV (85.7\% vs. 63.6\%, $p=0.07)$. In the 23 patients with a $\mathrm{PaCO}_{2}>45 \mathrm{mmHg}$, there were no significant differences in the above outcome variables between the two groups.

\section{DISCUSSION}

In patients with PERF, our study showed that HFNC exhibited a similar efficacy to NIV in terms of avoidance of reintubation in patients with PERF. In addition, HFNC was better tolerated, and associated with a shorter ICU stay, compared to NIV. In patients without hypercapnia (as indicated by a $\mathrm{PaCO}_{2}<45 \mathrm{mmHg}$ at the onset of PERF), HFNC was associated with lower ICU and in-hospital mortality rates than NIV.

Extubation is a critical step in patients who receive 
invasive mechanical ventilation. Despite recent advances in mechanical ventilation, PERF develops in $~ 10 \%$ to $20 \%$ of patients who meet weaning criteria $[1,2]$. Reintubation due to PERF is associated with poor outcomes and a mortality rate of up to $50 \%[3,5,6]$. Therefore, an effective intervention is required to prevent or reverse PERF to avoid reintubation. Previously, NIV was considered a promising therapy and recommended in patients with PERF [7]. However, two randomized studies failed to show beneficial effects of NIV in patients who develop respiratory failure after extubation. Indeed, the mortality rate was higher in the NIV group in two studies $[8,9]$. The benefit of NIV as a treatment for PERF was evident only in patients with hypercapnic respiratory failure $[18,19]$.

Heated and humidified HFNC was recently introduced to ICUs. It supplies up to $100 \%$ heated and humidified oxygen at a maximum flow rate of $60 \mathrm{~L} / \mathrm{min}$ via a nasal prong or cannula. By delivering a continuous high flow of oxygen, the pharyngeal dead space is washed out, nasopharyngeal resistance is reduced and some positive end expiratory pressure is generated, all of which contribute to a reduction in the work of breathing $[10,11]$. The heated humidification facilitates secretion clearance and expectoration of bronchial secretions. It also increases patient comfort because high-flow oxygen is delivered via a nasal cannula, and does not interrupt eating, drinking or talking. In addition, HFNC therapy has not been associated with pneumonia or barotrauma. A few reports have demonstrated the clinical benefits of HFNC, as shown by alleviation of symptoms and improvement of respiratory parameters such as respiratory rate, arterial blood oxygen partial pressure or saturation in patients with acute respiratory failure [12-15]. Two studies have reported that HFNC is equal or more effective than a simple mask in extubated patients in terms of tolerance and delivering oxygen [20,21]. However, the clinical efficacy of HFNC in PERF patients has not been reported to date. The present study indicates that HFNC is not inferior to NIV. Especially in patients with PERF without hypercapnia (i.e., PERF with dominant hypoxia), clinical outcomes such as duration of ICU stay and in-hospital mortality rate were more favorable with HFNC than with NIV. The clinical outcomes of PERF patients with hypercapnia did not differ significantly between HFNC and NIV.
There were several limitations to this study. First, because of its retrospective design and the small number of enrolled patients, the possibility of selection bias cannot be excluded. Second, as a single-center cohort was analyzed, the results cannot be generalized. Third, the group of patients with hypercapnic PERF was small, and so the results of comparison of HFNC and NIV in such cases should be verified.

In conclusion, HFNC may be at least equivalent to NIV in patients with PERF in terms of avoiding reintubation. HFNC oxygen therapy is associated with shorter ICU stay in patients with PERF. In subjects without hypercapnic PERF, ICU and in-hospital survival rates were improved by HFNC.

\section{KEY MESSAGE}

1. High-flow nasal cannula (HFNC) oxygen therapy was associated with shorter Intensive Care Unit stay in patients with post-extubational respiratory failure compared with noninvasive ventilation (NIV).

2. HFNC may not be inferior to NIV in terms of avoiding the need for reintubation.

\section{Conflict of interest}

No potential conflict of interest relevant to this article was reported.

\section{REFERENCES}

1. Epstein SK, Ciubotaru RL, Wong JB. Effect of failed extubation on the outcome of mechanical ventilation. Chest 1997;112:186-192.

2. Esteban A, Alia I, Gordo F, et al. Extubation outcome after spontaneous breathing trials with T-tube or pressure support ventilation: the Spanish Lung Failure Collaborative Group. Am J Respir Crit Care Med 1997;156(2 Pt 1):459-465.

3. Epstein SK, Ciubotaru RL. Independent effects of etiology of failure and time to reintubation on outcome for patients failing extubation. Am J Respir Crit Care Med 1998;158:489-493.

4. Torres A, Gatell JM, Aznar E, et al. Re-intubation increas- 
es the risk of nosocomial pneumonia in patients needing mechanical ventilation. Am J Respir Crit Care Med 1995;152:137-141.

5. Thille AW, Harrois A, Schortgen F, Brun-Buisson C, Brochard L. Outcomes of extubation failure in medical intensive care unit patients. Crit Care Med 2011;39:26122618.

6. Frutos-Vivar F, Esteban A, Apezteguia C, et al. Outcome of reintubated patients after scheduled extubation. J Crit Care 2011;26:502-509.

7. Organized jointly by the American Thoracic Society, the European Respiratory Society, the European Society of Intensive Care Medicine, and the Societe de Reanimation de Langue Francaise, and approved by ATS Board of Directors, December 2000. International Consensus Conferences in Intensive Care Medicine: noninvasive positive pressure ventilation in acute respiratory failure. Am J Respir Crit Care Med 2001;163:283-291.

8. Keenan SP, Powers C, McCormack DG, Block G. Noninvasive positive-pressure ventilation for postextubation respiratory distress: a randomized controlled trial. JAMA 2002;287:3238-3244.

9. Esteban A, Frutos-Vivar F, Ferguson ND, et al. Noninvasive positive-pressure ventilation for respiratory failure after extubation. N Engl J Med 2004;350:2452-2460.

10. Groves N, Tobin A. High flow nasal oxygen generates positive airway pressure in adult volunteers. Aust Crit Care 2007;20:126-131.

11. Ward JJ. High-flow oxygen administration by nasal cannula for adult and perinatal patients. Respir Care 2013;58:98-122.

12. Sztrymf B, Messika J, Bertrand F, et al. Beneficial effects of humidified high flow nasal oxygen in critical care patients: a prospective pilot study. Intensive Care Med
2011;37:1780-1786

13. Sztrymf B, Messika J, Mayot T, Lenglet H, Dreyfuss D, Ricard JD. Impact of high-flow nasal cannula oxygen therapy on intensive care unit patients with acute respiratory failure: a prospective observational study. J Crit Care 2012;27:324.e9-324.e13.

14. Roca O, Riera J, Torres F, Masclans JR. High-flow oxygen therapy in acute respiratory failure. Respir Care 2010;55:408-413.

15. Parke RL, McGuinness SP, Eccleston ML. A preliminary randomized controlled trial to assess effectiveness of nasal high-flow oxygen in intensive care patients. Respir Care 2011;56:265-270.

16. Manley BJ, Owen LS, Doyle LW, et al. High-flow nasal cannulae in very preterm infants after extubation. $\mathrm{N}$ Engl J Med 2013;369:1425-1433.

17. Esperatti M, Ferrer M, Theessen A, et al. Nosocomial pneumonia in the intensive care unit acquired by mechanically ventilated versus nonventilated patients. Am J Respir Crit Care Med 2010;182:1533-1539.

18. Nava S, Gregoretti C, Fanfulla F, et al. Noninvasive ventilation to prevent respiratory failure after extubation in high-risk patients. Crit Care Med 2005;33:2465-2470.

19. Ferrer M, Valencia M, Nicolas JM, Bernadich O, Badia JR, Torres A. Early noninvasive ventilation averts extubation failure in patients at risk: a randomized trial. Am J Respir Crit Care Med 2006;173:164-170.

20. Tiruvoipati R, Lewis D, Haji K, Botha J. High-flow nasal oxygen vs high-flow face mask: a randomized crossover trial in extubated patients. J Crit Care 2010;25:463-468.

21. Rittayamai N, Tscheikuna J, Rujiwit P. High-flow nasal cannula versus conventional oxygen therapy after endotracheal extubation: a randomized crossover physiologic study. Respir Care 2014;59:485-490. 